\title{
ERRATA
}

\section{Pock Formation of Streptomyces endus with Production of Phage Taillike Particles}

\author{
SEIYA OGATA, HIKARU SUENAGA, AND SHINSAKU HAYASHIDA
}

Laboratory of Applied Microbiology, Department of Agricultural Chemistry, Kyushu University, Fukuoka 812, Japan

Volume 43 , no. 5 , p. 1182: The title should read as given above.

\section{Measurement of Aquatic Biodegradation Rates by Determining Heterotrophic Uptake of Radiolabeled Pollutants}

\section{FREDERIC K. PFAENDER AND GENE W. BARTHOLOMEW}

Department of Environmental Sciences and Engineering, School of Public Health, University of North Carolina, Chapel Hill, North Carolina 27514

Volume 44, no. 1, p. 164: Table 3 should read as shown below (boldfaced values are corrections).

TABLE 3. Kinetic assessment of pollutant metabolism by Newport River Estuary microbial community

\begin{tabular}{lcccr}
\hline Compound & Date & $\begin{array}{c}\text { Temp } \\
\left({ }^{\circ} \mathrm{C}\right)\end{array}$ & $\begin{array}{c}\text { Turnover } \\
\text { rate }\left(\mathrm{h}^{-1}\right)^{a}\end{array}$ & $\begin{array}{c}\text { Maximum } \\
\text { metabolic velocity } \\
\left(\mathrm{ng}^{\prime} \cdot \text { liter }^{-1} \cdot \mathrm{h}^{-1}\right)^{b}\end{array}$ \\
\hline$m$-Cresol & $7 / 22 / 80$ & 26 & 0.0045 & 0 \\
& $8 / 10 / 80$ & 30 & 0.015 & 28 \\
& $10 / 20 / 80$ & 24 & 0.022 & 37 \\
& $12 / 5 / 80$ & 11 & 0.001 & 0.9 \\
Chlorobenzene & $4 / 3 / 81$ & 19 & 0.015 & 8.6 \\
& $7 / 22 / 80$ & 26 & 0.0002 & 0.6 \\
NTA & $9 / 25 / 80$ & 27 & 0.006 & $<0.1^{c}$ \\
Trichlorobenzene & $2 / 13 / 81$ & 6 & & 200 \\
& $11 / 7 / 80$ & 14 & $\mathbf{0 . 0 0 1 4}$ & $\mathbf{1 7 5}$ \\
\hline
\end{tabular}

${ }^{a}$ Turnover rate is the reciprocal of turnover time.

${ }^{b}$ Based on uptake plus respiration.

c Below the detection limit of the technique. 